\title{
THE FEAR OF LIFE HYPER-MEDICALISED SOCIETIES
}

Milagros Pérez Oliva

We are becoming more vulnerable. The feeling of general uncertainty comes from the fact that we live through several crises at the same time. In a world dominated by consumerism and self-interest, health has also become a consumer product. The wellness industry offers shortcuts to happiness and remedies to overcome the anxieties and discomforts of life: shortcuts and remedies in pill form. In this context, journalism must ensure access to truthful, evidence-based information that allows people to manage their decision-making properly, especially in situations concerning individual and collective health.

Keywords: medication consumption, promotion of disease, risk management, commercialisation of disease, welfare state.

\section{WE ARE MORE VULNERABLE}

We know that the more advanced a society is in terms of socio-economic development, the more its citizens resort to health care visits: we go more frequently to the doctor and consume more medication. But some indicators point to a part of the demand not being justified by actual pathological entities. The high consumption of antidepressants and anxiolytics is one of these indicators. Faced with this evidence, one may wonder: Are we really any sicker? Do we think we are sick? Or are we consuming health? We posit that all three occur at the same time: the changes that take place in the dominant socio-economic model make us more vulnerable; we are afraid and fight back any way we can; and fear and vulnerability are promoted and taken advantage of.

Let us look at these three factors in more detail. The first one is related to living in a rapidly changing world, in a transition period between a departing society model and an incoming one. We are in a state of change from an economic model based on social agreement -supported in advanced countries by the welfare state - to another, still incomplete, globalised and deregulated model, in which policy submits to the dictates of economy and imposes a productive model that increases inequality.

In reality, our feeling of general uncertainty comes from the fact that we live several crises at the same time whose effects synergise: the economic crisis, the ecological crisis, a crisis of values, of representative democracy, etc. The most noticeable one, the economic crisis that erupted in 2008, did nothing but exacerbate and accelerate the previously existing dynamics which generated a lot of distress.

We are living, therefore, in a time of change, marked by personal and collective uncertainty, which makes a lot of people feel insecure. The citizenry perceives that many of the welfare and social conquests of the last two centuries are in danger. If the economy fails, anyone can lose everything in a moment. In countries affected by the crisis, especially in southern Europe, the fear has emerged that the next generation will not be able to enjoy many of the advantages of their predecessors. Parents fear that their children will have a worse future. The children fear having no future. Fear of the future is closely related to the fear of exclusion. The 
latest crises have taught us that we are all vulnerable. Losing our job, still the main tool for personal development and social integration, is enough without the threat of other looming uncertainties. All this has changed our perception of the future. For the philosopher Daniel Innerarity (2009), «our relationship with the collective future is not based on hope and planning, but on precaution and improvisation».

This apprehension towards the future, together with our need to anticipate events, causes a lot of dysfunction in decision-making. We observed as much during the three global health care alerts of recent times: SARS (Severe Acute Respiratory Syndrome), avian flu and the influenza A virus. The terrified citizenry showed the same pattern of compulsive response in all three cases, and the same mistakes were made in all three. With the last two, the situation can be summarised as follows: in order to achieve a minimal response by the countries where the outbreak appeared -controlling the infection in the bird population - the World Health Organisation (WHO) issued a world alert that caused a hysterical and disproportionate reaction in rich Western societies, characterised by a strong aversion to involuntary risks. Even more seriously, these world alerts did not respond to real threats, but to the hypothetical: the possibility that the avian virus might mutate when in contact with human flu and create a new virus, as expansive as the human variety and as deadly as the avian one. Pure hypothesis, but both the media and health policy-makers put themselves in the worst possible scenario and acted accordingly, investing a lot of resources that would later prove to be useless.

The political struggle that only thinks about the present, the need to act ahead of time and the fear of being blamed for not foreseeing the consequences frequently leads politicians to take excessive preventive action. This anticipatory conduct contributes significantly to media culture, in Innerarity's opinion: «The new technologies of instantaneity favor a culture of absolute presentness with no temporal profundity» and the origin of this relationship in time is found in «the alliance established between the financial markets' goal of immediate gain and the instantaneousness of the media. We live in a time that is fascinated by velocity and overwhelmed by its own acceleration» (Innerarity, 2009). The media have become great generators of immediacy. The urgent frequently replaces the important, and in journalism impact is considered more relevant than importance.

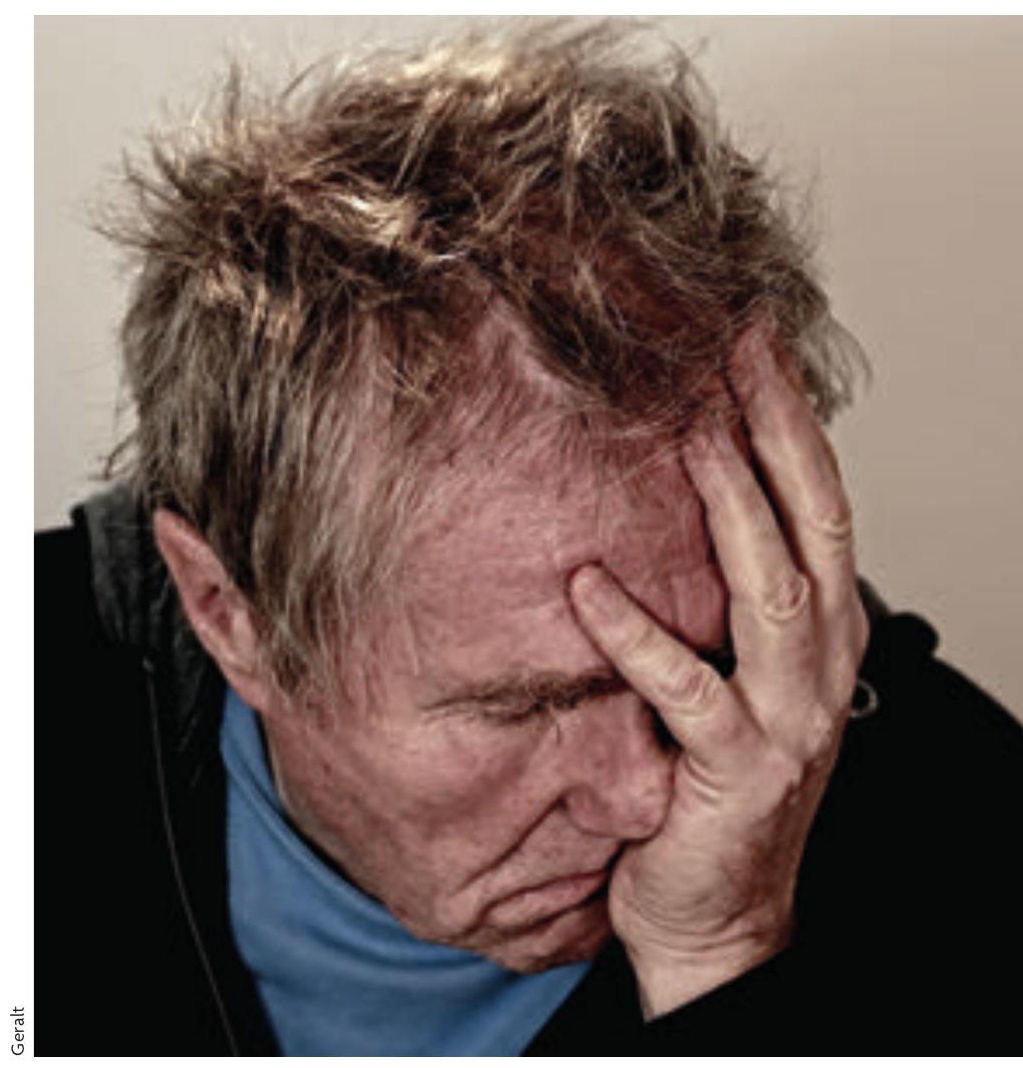

In the same way that occupational diseases in industrial societies are related with the production model (asbestosis, accidents, cancer related to exposure to toxins), in performance-driven societies the pathologies are related to the new forms of production and are mainly chronic fatigue, depression, and anxiety disorders.

\section{«THE URGENT FREQUENTLY REPLACES \\ THE IMPORTANT, AND IN JOURNALISM IMPACT IS CONSIDERED MORE RELEVANT THAN IMPORTANCE»}


This culture of urgency and consumerism, the culture of «I want it all and I want it now» that has been noted as an emerging trait is also reflected in terms of health. The impatient patient, who expects more than is reasonable from medications, is part of this culture of complaint; a culture founded on the idea of unlimited growth, which has now collapsed.

\section{WE ARE AFRAID AND WE FIGHT IT ANY WAY WE CAN}

An illusion maintained since the Enlightenment fractured for the first time: the idea that progress is an ever-ascending line, that there is no coming back from social conquests. Now we know we can go backwards. The words deregulation, offshoring, outsourcing and sustainability colonise the media and economic reports that try to justify the inevitability of a setback in the welfare state. With globalisation, the new booming values are now flexibility and mobility. But few ask who benefits primarily from those demands. Being flexible is fine, of course; it is always good to be able to adjust and adapt to new requirements. But what they want now is a beaten down populous. In a society

\section{"THE COMBINATION OF INSECURITY AND EXTREME COMPETITIVENESS IS TERRIBLE FOR HEALTH»} fabric? that quantifies everything in monetary terms, studies are undertaken to increase productivity, but not to analyse the costs involved. For instance, how much do we value the cost of alienation, of uprooting, of longlasting relationships? How much for the loss of social

The Korean philosopher who settled in Germany, Byung-Chul Han, analysed the costs of going from a «disciplinary society» to a «performance society» (Han, 2012). The old disciplinary society is based and organised on socially-powerful rules and institutions. It has regulated submission mechanisms, but also solidarity and collective defence mechanisms. Its central institutions are the factory, the school, the hospital and, for those who will not or cannot follow the rules, the prison and the psychiatric hospital. This society revolves around an agreement regarding production assets: some get profits, the others a salary.

The goal of the transition to a performance society, according to Byung-Chul Han, is to overcome the constraints of the model in order to increase productivity. Individuals in a performance society are still disciplined, but not so much by external rules - although they still exist in this social structure - but more by internal, self-imposed rules, to conform

to the new imperative that is performance. We move from exploitation to self-exploitation. From a demanding society to a self-demanding one. Selfexploitation is more effective and cheaper than exploitation. Performance societies are characterised by extreme deregulation and competitiveness. The new institutions are the office, remote working, the gym, the network, and the most important concept is the «can do» attitude. It starts with an assertion, «I can», but soon turns into an imperative: «you must», thus establishing a culture that requires permanent effort, which will always seem insufficient. This model often leads to frustration. Individuals are invited to have high expectations and strive to reach their ambitions. If they do not succeed, it is because they did not work hard enough or were not intelligent enough. This mentality leads these individuals to be at permanent war with themselves. In the same way that occupational diseases in industrial societies were related with the production model (asbestosis, accidents, cancer related to exposure to toxins), in performance-driven societies the pathologies are related to the new forms of production and are mainly chronic fatigue, depression, and anxiety disorders.
In a world dominated by consumerism and self-interest, health has also become a consumer product. The wellness industry offers shortcuts to happiness and remedies to overcome the anxieties and discomforts of life. Shortcuts and remedies in pill form. 
They become sick from «not being able to be a "can do" person anymore».

It is Zygmunt Bauman's concept of liquid life (2007), a type of social organisation where «the responsibility for resolving the quandaries generated by vexingly volatile and constantly changing circumstances is shifted onto the shoulders of individuals - who are now expected to be "free choosers" and to bear in full the consequences of their choices». In this new culture, the most useful virtue is not conforming to the rules, as it was in modern society, but rather, flexibility. What do we understand by flexibility in current culture? It is not only adaptability to a changing and accelerating situation. It is «a readiness to change tactics and style at short notice, to abandon commitments and loyalties without regret - and to pursue opportunities according to their current availability, rather than following one's own established preferences». The combination of insecurity and extreme competitiveness is terrible for health. As the sociologist Daniel Cohen (2001) already warned: the most usual consequences are depression and anxiety, even among adolescents, in addition to burnout syndrome.

\section{SOMEONE TAKES ADVANTAGE OF OUR VULNERABILITY}

In a world dominated by consumerism and self-interest, health has also become a consumer product. The wellness industry offers shortcuts to happiness and remedies to overcome the anxieties and discomforts of life. Shortcuts and remedies in pill form.

The North American psychiatrist Allen Frances, who directed the efforts of the Diagnostic and statistical manual of mental disorders-IV (DSM) is quite self-critical. He considers that the authors failed to foresee the amount of pressure the pharmaceutical industry would exert to extend diagnostics and use the new pathologies

The emergence of new treatments for hyperactivity was preceded by a lot of media reports on the pathology, how overlooked it was and how damaging it could be for the future of its patients.

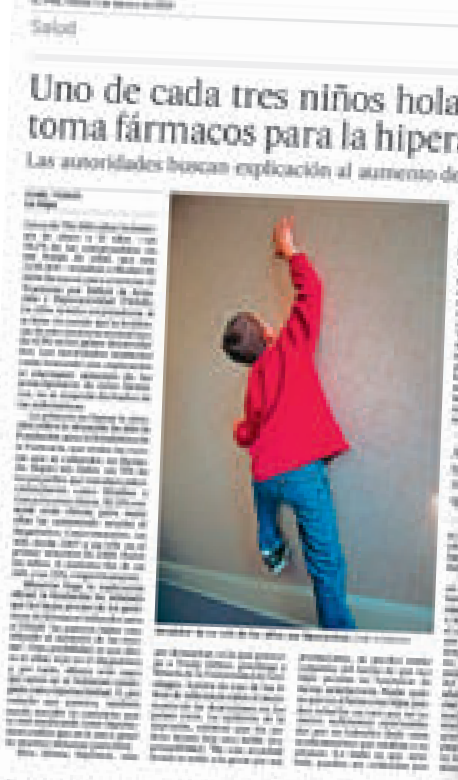

Espańa triplica los diagnósticos en cua
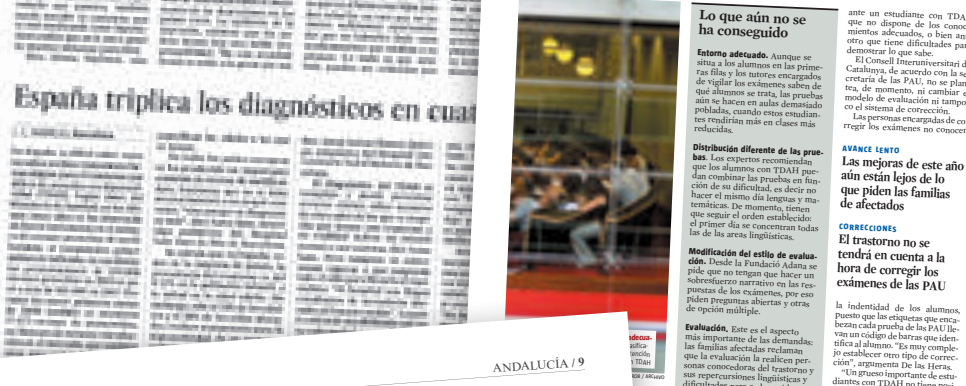

LA Consuitr

¿Cómo un niñ

$\mathrm{U}$

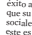

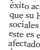

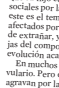

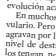

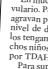

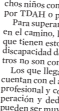

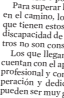

res y maes

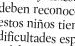

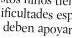

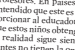

Los expertos alertan de que la hiperactividad $\begin{aligned} & \text { profesores para } \\ & \text { atajar la violencia } \\ & \text { en las aulas }\end{aligned}$

$\begin{array}{ll}\text { Los expertos alertan de que la hiperactividad } & \begin{array}{l}\text { profesores par } \\ \text { atajar la viol }\end{array} \\ \text { en las aulas }\end{array}$ podría afectar al $7 \%$ de los escolares

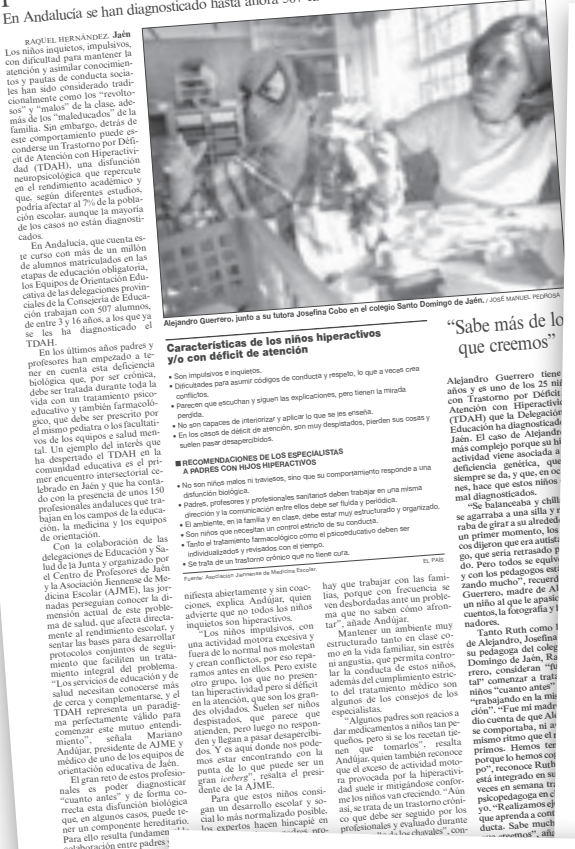

34 LVNAGCARDA $S O C I$ DAD

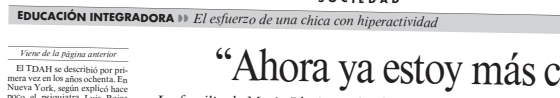

La familia de Maria Llavina se ha desvivido para que su hija pud

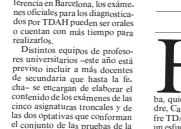

$\mathrm{H}$

Hivis

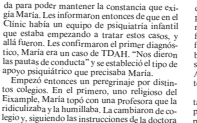

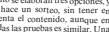

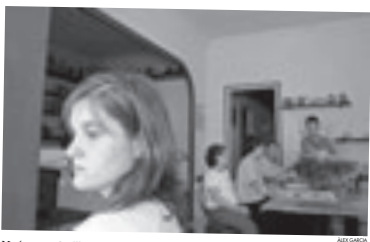

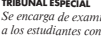

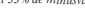

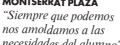

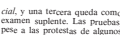

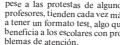

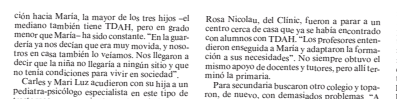

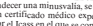

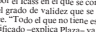

Caracteristices do los nitosy a si

Caracteristicas de los niños y las niñas con TDAH y suged
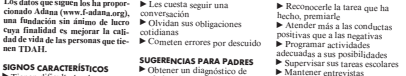

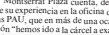

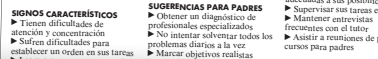

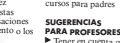
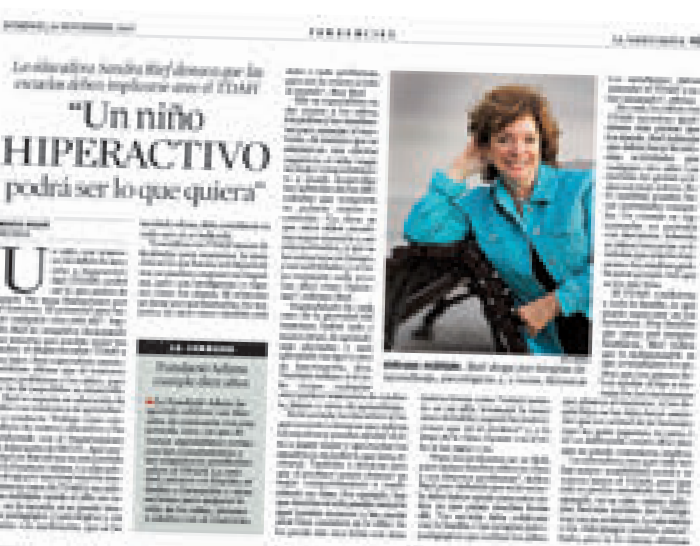


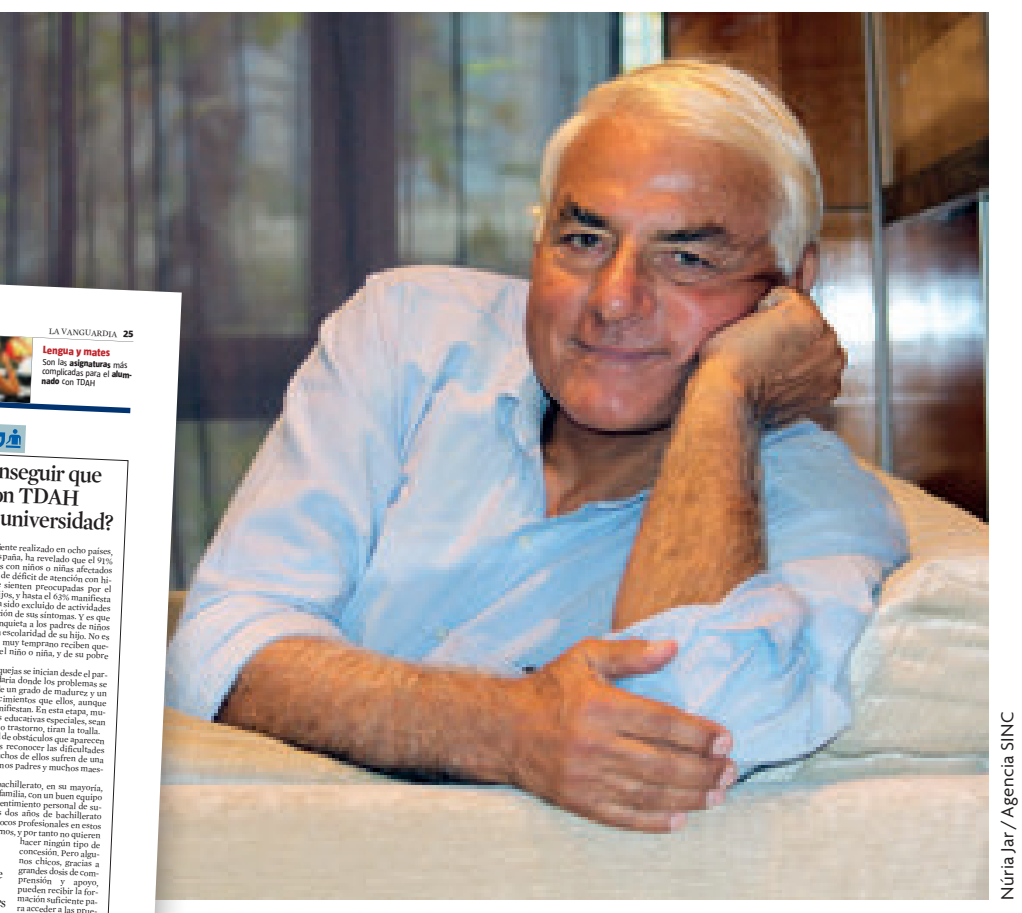

The North-American psychiatrist Allen Frances (in the picture), who coordinated the fourth edition of the Diagnostic and statistical manual of mental disorders, is very self-critical. He considers that the authors failed to foresee the amount of pressure the pharmaceutical industry would exert to extend diagnostics and use the new pathologies described in the reference psychiatry manual for their own benefit.

described in the reference psychiatry manual for their own benefit (Frances, 2014). The result is the over-diagnosis of some entities such as depression, hyperactivity and attention deficit, or autism spectrum disorders, and a tendency to medicate all aspects of life and any and every setback. He argues that this has led to normal life processes such as menopause, mourning or restlessness being treated as mental illnesses.

The new version of the manual, the DSM-V, approved in May 2013, aggravated the problem by expanding the number of mental disorders even further. It also established lower diagnostic thresholds, which significantly increases the range of conducts considered to be pathological and thus susceptible to medical treatment. The combination is creating a diagnostic hyperinflation with huge social costs and, even worse, which has negative effects on the health of many people. Pharmacological treatments are not innocuous and over-medication can have serious sideeffects (Frances, 2014).
One of the clearest examples is that of hyperactivity and attention deficit disorder. In late 2008, a study by the Dutch Foundation for Pharmaceutical Statistics which included 750,000 children and teenagers aged from five to fifteen found that $34.2 \%$, one in three children, took drugs such as Ritalin or Concerta for attention deficit and hyperactivity disorder, and interestingly, $75 \%$ of the treated children were male. The increase had been so spectacular and fast that the Dutch health authorities opened an investigation to determine the causes behind such over-medication. The true incidence of hyperactivity and attention deficit disorder is estimated at around $2-3 \%, 5 \%$ at most. A similar phenomenon was also observed in the United States: $11 \%$ of children have been diagnosed with the disorder. Among boys, the percentage reaches $20 \%$, half of whom receive pharmacological treatment.

All these increases coincide with the dates when new drugs for these disorders were marketed and when pharmaceutical companies developed promotional campaigns for them. Moynihan, Heath and Henry (2002) have explained in depth what disease mongering is: the promotion of disease as a result of the strategy laboratories follow to expand the market for their products. The emergence of new treatments for hyperactivity was preceded by a lot of media reports on the pathology, how overlooked it was and how damaging it could be for the future of its patients. The same thing happened with other commercial targets such as hormone replacement therapy to treat menopause and its side-effects, Viagra for erectile dysfunction or Prozac for depression.

The strategy is clear: raising awareness about a health issue with a systematic media campaign using the scientific and medical community as a source of authority. The first stage of the strategy is to colonise the media with expert voices and, when possible, with demands from affected people, to whom a solution is later offered in the form of pills. In some cases, these strategies go beyond the promotion of new treatments. They have also been used to take advantage and give a second wind to old drugs by assigning new indications to some that had lost their patent or that were languishing in a portfolio. This is what happened with the promotional campaign for the «shyness pill», an antidepressant that enjoyed a second life when it started being indicated for a new pathological entity 


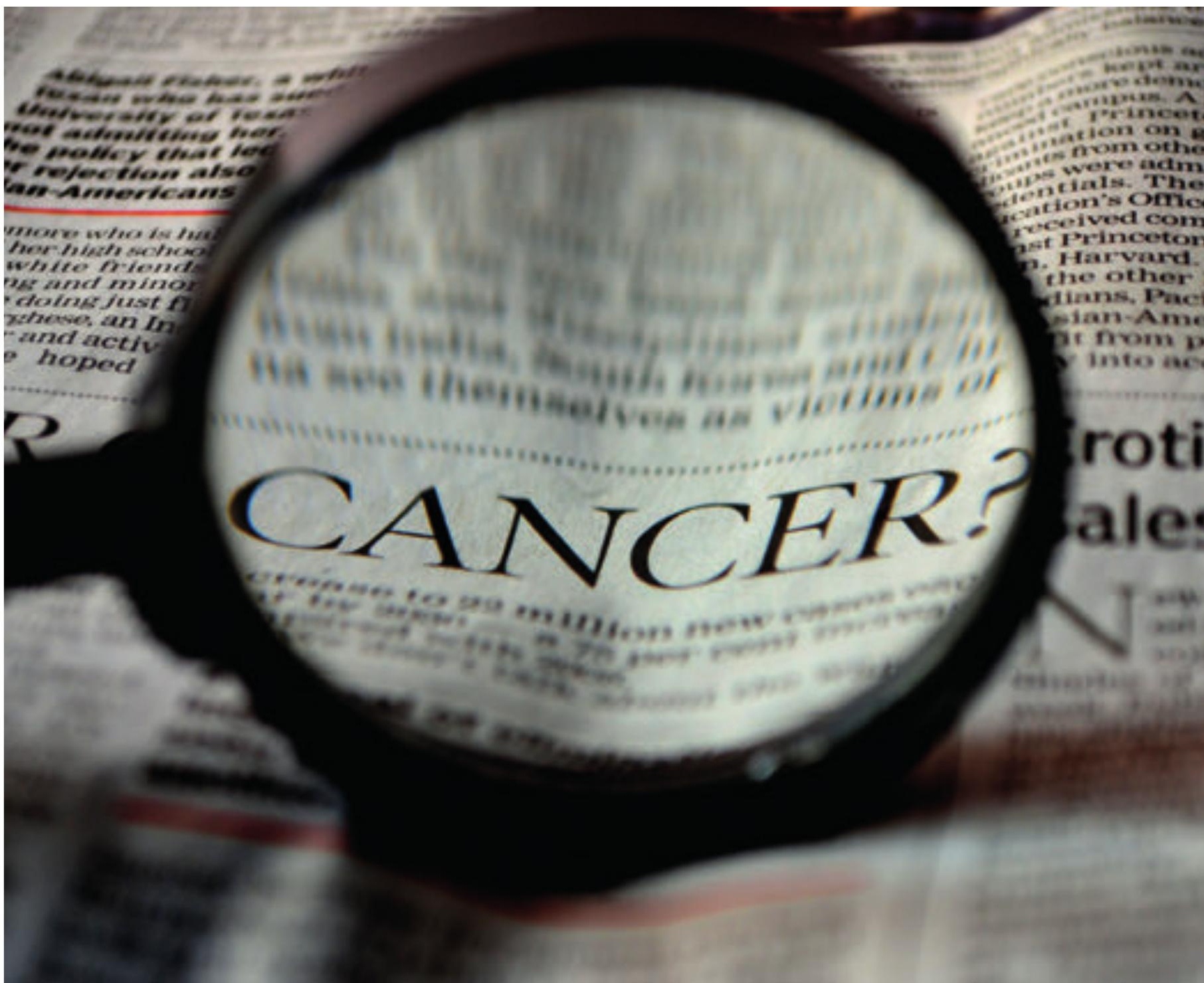

To manage our lives and the change around us, to understand the increasingly complex reality of things, we need huge amounts of good information.

redefined to suit it: social phobia. Unfortunately it has been a long time since pharmaceutical laboratories have been managed by pharmacologists who care about patients' health needs, rather, they are run by CEOs from business schools whose main objective is the short-term maximisation of profit. The old paradigm of a «disease looking for a drug» has been replaced in many cases by «the drug looking for a disease».

All of this, about which so much has been written, is true. But it is not enough to explain the level of over-diagnosis that some pathologies have reached, especially in mental health. As much as laboratories lobby and incentivise psychiatrists, which they do,
«THE OBSESSION WITH PREVENTING AND ANTICIPATING WHAT MIGHT HAPPEN, IS ON TRACK TO BECOMING A NEW SOCIAL PATHOLOGY. IN OTHER WORDS: LABORATORIES' STRATEGIES FOR INCREASING THEIR MARKETS AND FOR REACHING COMMERCIAL TARGETS PLAYS A DECISIVE ROLE IN THE GROWING MEDICALISATION OF LIFE" 


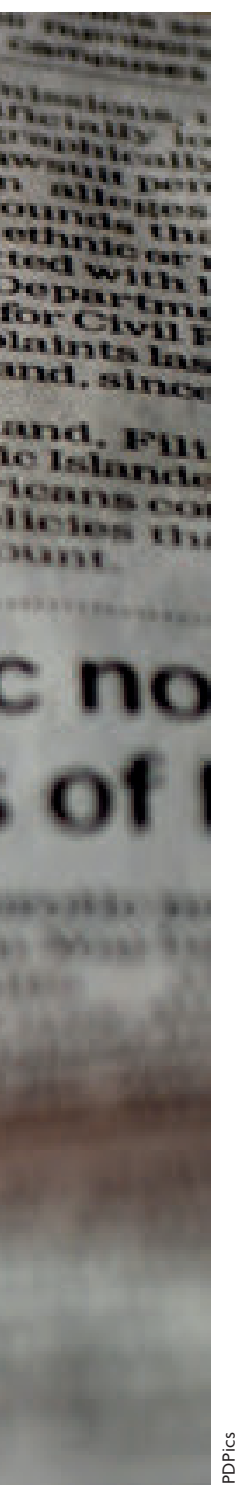

the doctors would not be able to prescribe drugs for hyperactivity and attention deficit if there were no distressed parents bringing their children for consultations. In changeable and insecure socio-economic conditions, distress becomes an everyday experience. Even if we have security today, we know that we can lose it tomorrow, and each setback reduces the chances of success. When parents observe that their children do not progress adequately, or they have learning difficulties or an unexpected conduct, they panic and run to the psychiatrist's office. The obsession with preventing and anticipating what might happen, is on track to becoming a new social pathology. In other words: laboratories' strategies for increasing their markets and for reaching commercial targets plays a decisive role in the growing medicalisation of life.

However, the strategy would fall on deaf ears were it not because the social conditions of fear, anxiety and depression push many people towards medicine to look for a remedy to the social ills they suffer.

The sociologist Zigmunt Bauman described it very accurately:

Instead of great expectations and sweet dreams, «progress» evokes an insomnia full of nightmares of «being left behind» - of missing the train, or falling out of the window of a fast accelerating vehicle.

Unable to slow the mind-boggling pace of change, let alone predict and control its direction [...] we are engrossed in spying out [...] «the five symptoms of depression», or in exorcising the spectre of high blood pressure, a high cholesterol level, stress or obesity. [...] But we do so compulsively, we commit ourselves to compulsive health purchasing in the labels of the products we use. The industry of fear does not profit only from guns and security, but also from health trade.

(Bauman, 2007)

In terms of the community, in order to avoid such an unhealthy drift it is important to correctly characterise the nature of current changes and to analyse the factors involved in the processes that lead to the excessive medicalisation of life. Otherwise, it will be difficult to resist the pressure and develop the social resilience required to cope with the insecurity and discomfort derived from a socio-economic order based on competitiveness, deregulation and extreme individualism. As the philosopher Marina Garcés (2013) stated, this will help us to develop ways to resist that do not only slow down this tendency, but that also lay the groundwork for an alternative. The antidote for the anxiety of «not being able be a "can do" person» is precisely to collectively state the supremacy of collectivity over nihilism - lest it leads to consumerist individualism.

It is very important to be able to debate our experiences and direction through deliberative processes that prevent compulsive decisions dictated by urgency or subjectivity. For this purpose, it is essential to have good information. Information is a key element in the decision-making process of a complex society. The American philosopher Henry G. Frankfurt (2007) regrets that in recent years the value of truth has been dismissed under the theory that there are as many truths as individuals. It is not

true. There can be as many interpretations of reality as individuals, but there is one single truth, the truth that comes from data and verifiable facts, to which journalism must serve. To manage our lives and the change around us, to understand the increasingly complex reality of things, we need huge amounts of good information. The main social function of journalism is to guarantee complete and truthful information.

\section{REFERENCES}

Bauman, Z. (2007). Tiempos líquidos. Vivir en una época de incertidumbre. Barcelona: Tusquets.

Cohen, D. (2001). Nuestros tiempos modernos. Barcelona: Tusquets. Frances, A. (2014). ¿Somos todos enfermos mentales? Barcelona: Ariel. Frankfurt, H. G. (2007). Sobre la verdad. Barcelona: Paidós. Garcés, M. (2013). Un mundo común. Barcelona: Bellaterra. Han, B-Ch. (2012) La sociedad del cansancio. Barcelona: Herder. Innerarity, D. (2009). El futuro y sus enemigos. Una defensa de la esperanza política. Barcelona: Paidós.

Moynihan, R., Heath, I., \& Henry, D. (2002). Selling sickness: The pharmaceutical industry and disease mongering. British Medical Journal, 324, 886-890. doi: 10.1136/bmj.324.7342.886

\footnotetext{
Milagros Pérez Oliva. Journalist, Head of the El País Area of Biomedicine and its health supplement. From 2009 to 2012 she was also the Reader's Ombudsman for the newspaper. She is Professor of the $E l$ País Masters Degree in Journalism at the Autonomous University of Madrid (Spain) and of the Masters Degree in Scientific, Medical and Environmental Communication in the Pompeu Fabra University in Barcelona (Spain). Her journalistic career has been recognised with several prizes; among them: the National Journalism Award 2006 from the Generalitat de Catalunya (Catalan regional government), the award of the Spanish Society of General Medicine (2007), the Boehringer Ingelheim Award for Medical Journalism (2009) and the Margarita Rivière prize (2015)
} 